\title{
Perioperative care after thoracoabdominal aortic aneurysm repair: The Baylor College of Medicine experience. Part 2: Postoperative management
}

Subhasis Chatterjee, MD, ${ }^{\mathrm{a}, \mathrm{b}}$ Jose G. Casar, MD, ${ }^{\mathrm{b}}$ Scott A. LeMaire, MD, ${ }^{\mathrm{b}, \mathrm{c}, \mathrm{d}}$ Ourania Preventza, MD, ${ }^{\mathrm{b}, \mathrm{c}, \mathrm{d}}$ and Joseph S. Coselli, MD ${ }^{\mathrm{b}, \mathrm{c}, \mathrm{d}}$

Video clip is available online.

\section{FUNDAMENTALS OF POSTOPERATIVE CARE}

The fundamentals of operative techniques of thoracoabdominal aortic aneurysm repair (TAAAR) have been described in detail. ${ }^{1,2}$ On the patient's arrival in the intensive care unit (ICU), a sign-out should include intraoperative details: repair extent (Figure 1), cardiopulmonary tolerance of the procedure, concomitant procedures, renaland mesenteric-vessel management, degree of bleeding, and distal vascular pulse findings obtained before the patient leaves the operating room. To prevent complications related to spinal cord deficit (SCD), acute kidney injury (AKI), and respiratory failure, vital signs are monitored, focusing on core temperature, mean arterial pressure (MAP), central venous pressure (CVP), pulmonary arterial (PA) pressures, and cardiac output (Table 1 and Video 1). To avoid hypotension and postoperative $\mathrm{SCD}$, volume resuscitation is guided by invasive monitoring to achieve a CVP of 8 to $12 \mathrm{~mm} \mathrm{Hg}$ or a diastolic PA pressure $>12 \mathrm{~mm} \mathrm{Hg}$.

\section{POSTOPERATIVE CONSIDERATIONS}

\section{Neurologic}

As the patient awakens from anesthesia, any focal neurologic deficit requires prompt imaging to exclude hemorrhage. The overall incidence of permanent stroke after TAAAR is low $(2 \%)$ in our experience ${ }^{3}$; it is greater $(9 \%)$ after the rare $(1.5 \%)$ cases requiring hypothermic circulatory arrest. ${ }^{4}$ However, Kouchoukos and colleagues ${ }^{5}$ had

\footnotetext{
From the Divisions of ${ }^{\mathrm{a}}$ General Surgery and ${ }^{\mathrm{b}}$ Cardiothoracic Surgery, Michael E. DeBakey Department of Surgery, Baylor College of Medicine; ${ }^{\mathrm{c} D e p a r t m e n t}$ of Cardiovascular Surgery, Texas Heart Institute; and ${ }^{\mathrm{d}}$ Department of Cardiovascular Surgery, CHI St Luke's Health—Baylor St Luke's Medical Center, Houston, Tex.

Dr LeMaire's work is partially supported by the Jimmy and Roberta Howell Professorship in Cardiovascular Surgery at Baylor College of Medicine.

Received for publication Aug 26, 2019; revisions received Nov 1, 2019; accepted for publication Nov 21, 2019; available ahead of print Feb 19, 2020.

Address for reprints: Subhasis Chatterjee, MD, One Baylor Plaza, BCM390, Houston, TX 77030 (E-mail: Subhasis.Chatterjee@bcm.edu).

J Thorac Cardiovasc Surg 2021;161:699-705

Copyright (c) 2020 by The American Association for Thoracic Surgery

https://doi.org/10.1016/j.jtcvs.2019.11.143
}

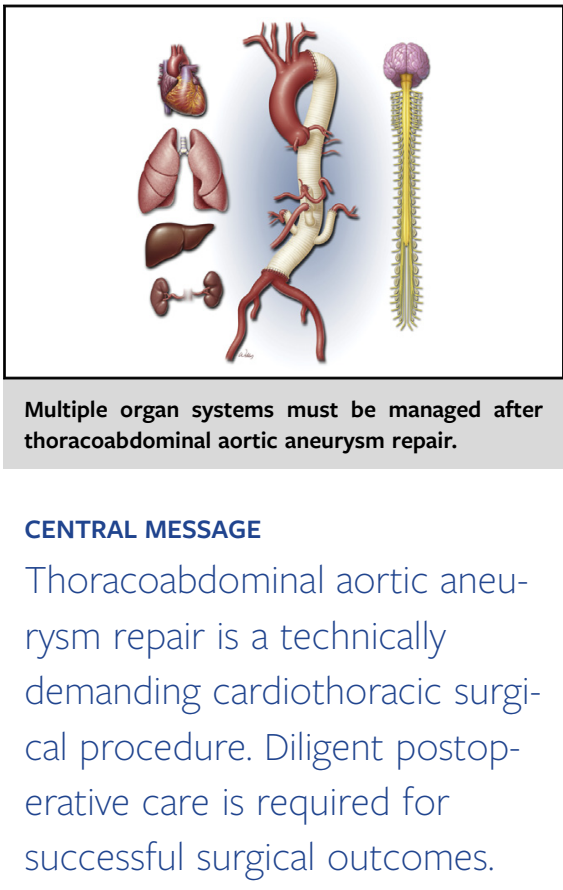

See Commentary on page 706. a $3.7 \%$ stroke incidence with routine hypothermic circulatory arrest.

Spinal cord deficit. A critical focus of post-TAAAR management is minimizing the risk of SCD (paraplegia or paraparesis). The incidence of temporary (2.4\%) and permanent $(5.4 \%)$ SCD is influenced by TAAAR extent: Permanent SCD is more frequent after the more extensive extent II $(8.0 \%)$ and extent III $(7.0 \%)$ repairs than after extent I $(3.4 \%)$ and extent IV (2.4\%) repairs. ${ }^{3}$ Intraoperative strategies to prevent SCD include left heart bypass in extent I and II TAAAR patients ${ }^{6}$ and cerebrospinal fluid (CSF) drainage in extent I, II, and selected extent III patients. For TAAAR, CSF drainage is recommended in the American (Class IB) ${ }^{9}$ and European (Class IIA) ${ }^{10}$ guidelines. Over the past decade, our CSF drain use has been as follows: extent I (97\%), extent II $(98 \%)$, extent III $(77 \%)$, and extent IV (36\%). Before elective and (whenever possible) emergency repairs, a $14-\mathrm{G}$ needle is inserted into a lower lumbar interspace (L3-L4 or L4-L5), and the 

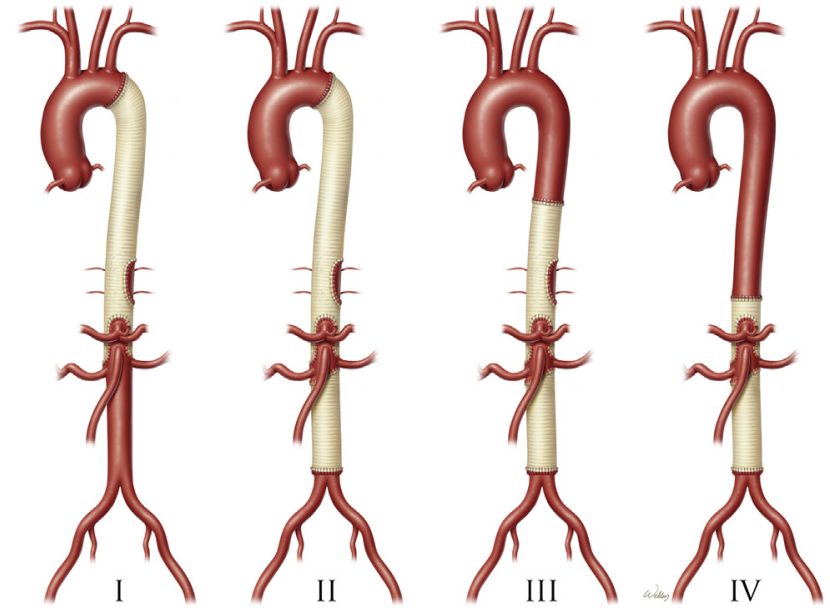

FIGURE 1. Crawford classification of the extent of thoracoabdominal aortic aneurysm repairs. The risk of spinal cord deficit is greatest with extent II and III aneurysms.

CSF drain is advanced until CSF is obtained ${ }^{11}$; this is done in the operating room by senior anesthesiologists after anesthesia is induced. If blood is encountered during CSF drain placement, we either defer the case (if it is elective) or postpone drain placement until after TAAAR in the operating room. Similarly, if the patient is hemodynamically unstable, then drain placement is deferred until after TAAAR. Other centers may place the CSF drain under fluoroscopic guidance; we selectively use that approach in patients with previous lumbar fusion surgery or Harrington rods (eg, Marfan patients).

Spinal cord perfusion pressure is the difference between systemic MAP and CSF pressure; its goal value is $>65 \mathrm{~mm}$ $\mathrm{Hg}$. Postoperatively, the target MAP is 85 to $100 \mathrm{~mm} \mathrm{Hg}$, greater in patients with greater baseline hypertension or more extensive renal/visceral artery reconstruction. Other high-volume centers have slightly different MAP goals (eg, $75-85 \mathrm{~mm} \mathrm{Hg}$ at the University of Pennsylvania, ${ }^{12}$ $80-90 \mathrm{~mm} \mathrm{Hg}$ at Mount Sinai ${ }^{13}$ ). Adequate volume resuscitation, guided by CVP and PA pressure, is critical, after which MAP must be maintained above $85 \mathrm{~mm} \mathrm{Hg}$ with norepinephrine and vasopressin infusions. Severe, uncontrolled hypertension (MAP $>120 \mathrm{~mm} \mathrm{Hg}$ ) can cause anastomotic bleeding, resulting in catastrophic hemorrhage, hypotension, emergency surgical salvage, and death. To avoid exceeding 115 to $120 \mathrm{~mm} \mathrm{Hg}$, nicardipine is our first-choice vasodilator, followed by esmolol. One should

TABLE 1. Summary: goals of postoperative management

\begin{tabular}{|c|c|c|}
\hline Organ/system & Goals & Interventions \\
\hline Vital signs & Restore normothermia & Warmed fluids, patient-warming devices \\
\hline Brain & Recognize focal neurologic deficits & Diagnostic imaging as needed \\
\hline \multirow[t]{4}{*}{ Spinal cord } & Mean arterial pressure $85-100 \mathrm{~mm} \mathrm{Hg}$ & $\begin{array}{l}\text { Volume resuscitation } \\
\text { Vasopressors (norepinephrine, vasopressin) or vasodilators } \\
\quad \text { (nicardipine, esmolol) }\end{array}$ \\
\hline & CSF drainage $<15 \mathrm{~mm} \mathrm{Hg}$ & Hourly check of CSF pressure and drainage as needed $(<10 \mathrm{~mL} / \mathrm{h})$ \\
\hline & Lower-extremity movement & Neurologic exam checks \\
\hline & & Suspect spinal cord deficit (Figure 2) \\
\hline \multirow[t]{3}{*}{ Pulmonary } & Lung-protective ventilation & Ventilator adjustment \\
\hline & Vocal cord function & Direct laryngoscopy if vocal cord dysfunction suspected \\
\hline & & Injection laryngoplasty if movement impaired \\
\hline \multirow[t]{5}{*}{ Cardiovascular } & Central venous pressure $8-12 \mathrm{~mm} \mathrm{Hg}$ & Volume resuscitation \\
\hline & $\begin{array}{l}\text { Pulmonary artery diastolic pressure } \\
12-16 \mathrm{~mm} \mathrm{Hg}\end{array}$ & \\
\hline & Cardiac index $\geq 2.2 \mathrm{~L} / \mathrm{min} / \mathrm{m}^{2}$ & Volume resuscitation \\
\hline & & Epinephrine, dobutamine infusion \\
\hline & Restore sinus rhythm & Amiodarone, cardioversion \\
\hline \multirow[t]{2}{*}{ Renal, fluids, electrolytes } & $\begin{array}{l}\text { Adequate resuscitation; crystalloid } \\
\text { at } 1.5-2.0 \mathrm{~mL} / \mathrm{kg} / \mathrm{h}\end{array}$ & Check serum lactate, base deficit, urine output \\
\hline & Prevent acute kidney injury & $\begin{array}{l}\text { Adequate volume and mean arterial pressure, rounding with } \\
\text { pharmacy, medication adjustments, avoid nephrotoxins/contrast, } \\
\text { avoid subclavian and peripherally inserted central catheters }\end{array}$ \\
\hline Gastrointestinal & Return of bowel function & Nasogastric tube, cautious advancement of diet \\
\hline \multirow[t]{4}{*}{ Hematologic } & Hemoglobin $9.5-10.5 \mathrm{~g} / \mathrm{dL}$ & Transfusion as needed \\
\hline & Platelets $\geq 100,000$ & \\
\hline & International normalized ratio $\leq 1.6$ & \\
\hline & Fibrinogen $\geq 200,000$ & \\
\hline
\end{tabular}

CSF, Cerebrospinal fluid. 


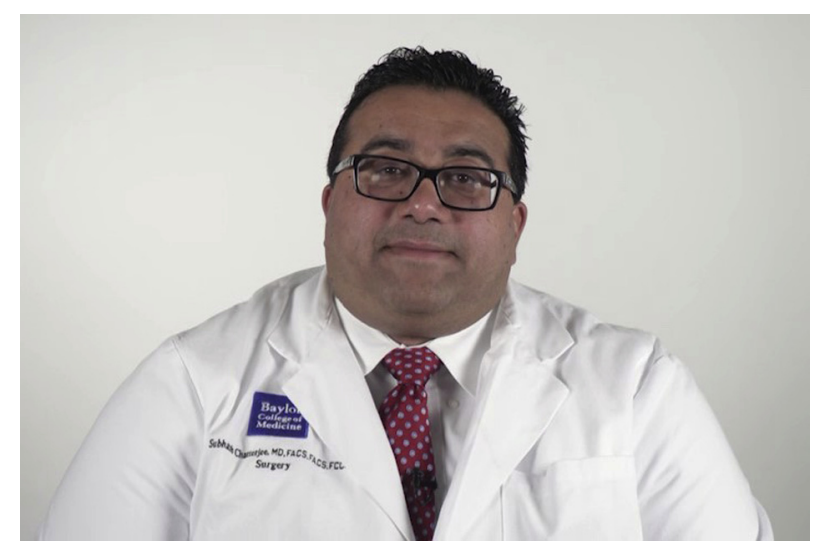

VIDEO 1. Dr. Chatterjee highlighting the major postoperative considerations after thoracoabdominal aortic aneurysm repair. These include resuscitation, efforts to reduce the risk of spinal cord deficit, maintaining adequate hemodynamics, and strategies to reduce pulmonary and renal complications. Video available at: https://www.jtcvs.org/article/S00225223(20)30201-4/fulltext.

be vigilant about delayed SCD, given the catastrophic risks of permanent disability and death. ${ }^{14}$ Up to $60 \%$ of temporary SCD cases follow a hypotensive episode, and symptoms can arise up to 27 days after TAAAR. ${ }^{15}$ In our study of
1114 extent II procedures, 39 patients (3.5\%) developed delayed persistent paraplegia or paraparesis; of these events, $45 \%$ occurred within 2 days after surgery and $35 \%$ during postoperative days 3 to 5 , suggesting patients are most vulnerable soon after surgery. ${ }^{16}$ In a series from Washington University, the average MAP of patients with delayed SCD was $74 \mathrm{~mm} \mathrm{Hg}$ at diagnosis and $95 \mathrm{~mm} \mathrm{Hg}$ at recovery. ${ }^{12}$ Moreover, The University of Texas/Memorial Hermann group observed that even a 15-mm Hg fluctuation in systolic blood pressure over 24 hours tripled the delayed SCD risk. ${ }^{17}$

Causes of unexplained relative hypotension (eg, bleeding, excessive diuresis, dysrhythmias, vasodilatory/ septic shock) should be investigated. Others ${ }^{13}$ have routinely used 48 to 72 hours of glucocorticoids; we have not. The patient's hemoglobin level is kept at 9.5 to $10.5 \mathrm{~g} / \mathrm{dL}$ with packed red blood cell transfusions. In patients with a prolonged ICU course and without signs of $\mathrm{SCD}$, the transfusion threshold is lowered to a hemoglobin level of 8.5 to $9.5 \mathrm{~g} / \mathrm{dL}$.

The TAAAR is performed with permissive hypothermia near $32^{\circ} \mathrm{C}$; patients typically arrive in the ICU at $33^{\circ} \mathrm{C}$ to $34^{\circ} \mathrm{C}$. Gradual rewarming to normothermia is continued with a whole-body Bair Hugger (3M, St Paul, Minn) and resuscitation with warmed intravenous fluids and blood

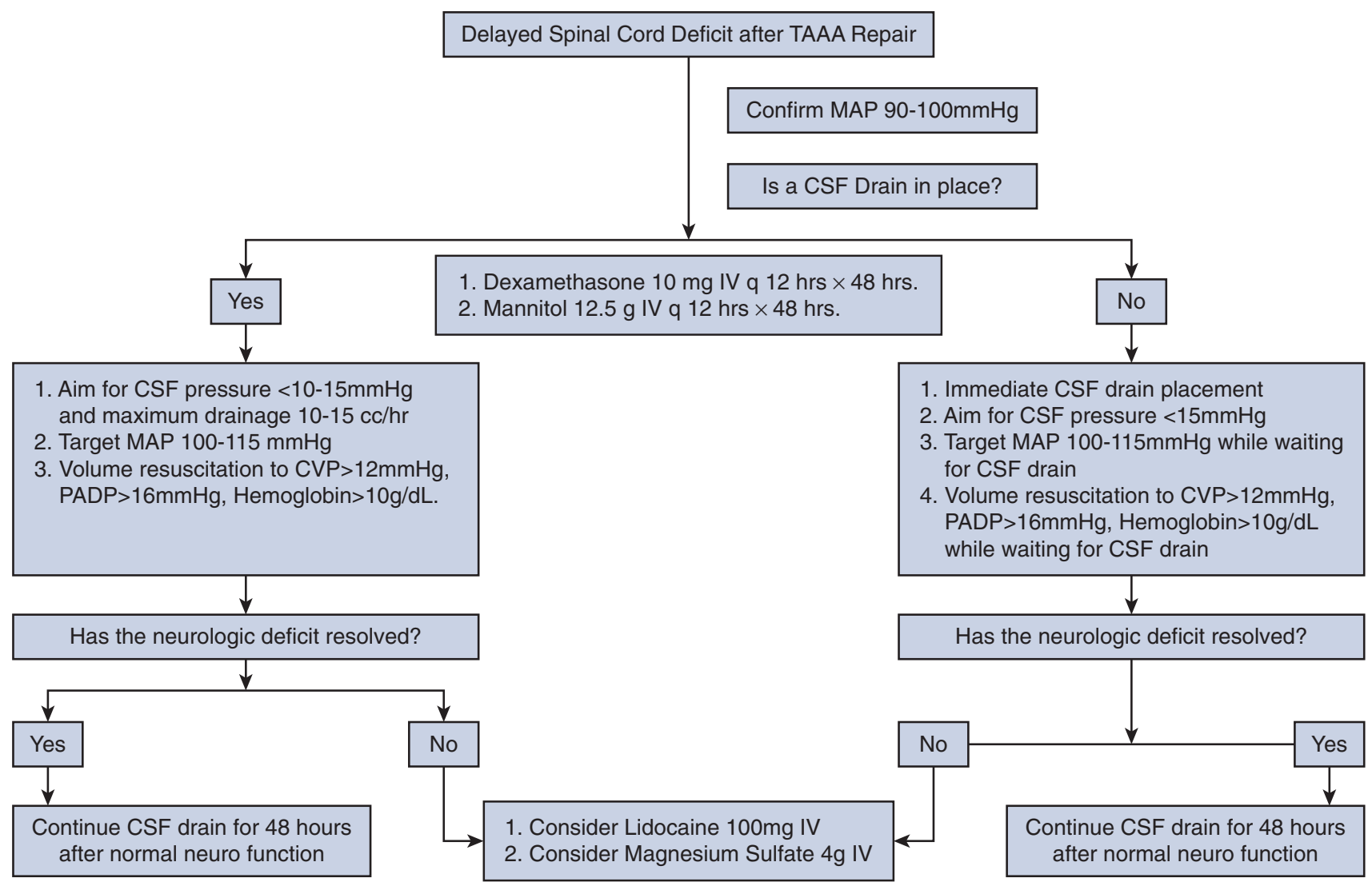

FIGURE 2. Coselli/Baylor management algorithm for spinal cord deficit after TAAA repair. Aggressive intervention can increase the chance for successful recovery. TAAA, Thoracoabdominal aortic aneurysm repair; $M A P$, mean arterial pressure; $C S F$, cerebrospinal fluid; $I V$, intravenous; $C V P$, central venous pressure; $P A D P$, pulmonary artery diastolic pressure. 
products. Extubating shivering patients can lead to demand ischemia, decreased cardiac output, and SCD risk. As warming proceeds, clinicians should anticipate systemic vasodilation, which can lower venous return and MAP. We avoid treating moderate hypertension during the patient's hospitalization and recommend waiting 4 to 6 weeks postoperatively before resuming strict hypertension management.

Postoperatively, the CSF pressure is typically kept at $<15 \mathrm{~mm} \mathrm{Hg}$. We avoid draining CSF at $>150 \mathrm{~mL} / 24 \mathrm{~h}$, $>25 \mathrm{~mL} / 4 \mathrm{~h}$, or $>10 \mathrm{~mL} / \mathrm{h}$. This is comparable with the University of Pennsylvania's target pressure of $\leq 12 \mathrm{~mm} \mathrm{Hg} .{ }^{12}$ The baseline CSF pressure and amount drained should be discussed with anesthesiology. We have seen catastrophic cases of subdural hematoma, subarachnoid hemorrhage, and other central nervous system bleeds from excessive drainage.

If signs of paraplegia or paraparesis appear, rescue measures must be initiated (Figure 2) as follows: Immediately confirm the MAP is 90 to $100 \mathrm{~mm} \mathrm{Hg}$. If the CSF drain has been removed, an anesthesiologist is immediately consulted for a new CSF drain while other adjunctive measures are started. The target CSF pressure is lowered to $<15 \mathrm{~mm}$ $\mathrm{Hg}$, and the CSF drainage rate is cautiously increased to 10 to $15 \mathrm{~mL} / \mathrm{h}$, with a maximum of $50 \mathrm{~mL} / 4 \mathrm{~h}$. The patient is placed in the Trendelenburg position, and the following are increased: target MAP to 100 to $115 \mathrm{~mm} \mathrm{Hg}$, CVP to $>10$ to $12 \mathrm{~mm} \mathrm{Hg}$, and hemoglobin level to $>10 \mathrm{~g} / \mathrm{dL}$. The CVP should not be excessively increased because this could raise intracerebral and CSF pressure.

Ours and other high-volume TAAAR centers have delayed-paraplegia-management algorithms. The University of Texas/Memorial Hermann group's "COPS" protocol $(\mathrm{C}=\mathrm{CSF}$ drain status, $\mathrm{O}=$ oxygen delivery, $\mathrm{PS}=$ patient state $)^{18}$ differs subtly from our protocol: Their target CSF pressure $(<5 \mathrm{~mm} \mathrm{Hg})$ is lower than ours, we remove the drain before the 5 days recommended in the COPS protocol, and our goal hemoglobin level $(10 \mathrm{~g} / \mathrm{dL})$ is lower than the COPS protocol's $>12 \mathrm{mg} / \mathrm{dL}$ target. The University of Pennsylvania group aims for MAP of 90 to $100 \mathrm{~mm} \mathrm{Hg}$ and CSF pressure $<10 \mathrm{~mm} \mathrm{Hg.}{ }^{12}$ Nevertheless, the fundamental principles are similar: increase spinal cord perfusion pressure and maximize oxygen delivery. Once spinal cord ischemia is suspected, intravenous mannitol (12.5 g) and dexamethasone $(10 \mathrm{mg})$ are given every 12 hours for 48 hours. If symptoms do not improve after CSF drain placement and increasing target MAP and volume resuscitation, single rescue doses of intravenous lidocaine $(100 \mathrm{mg})$ and magnesium sulfate ( $4 \mathrm{~g}$ ) may be administered. The Cleveland Clinic group has used intrathecal papaverine with encouraging results, ${ }^{19}$ and anecdotal reports describe successful hyperbaric oxygen therapy and hypothermia. ${ }^{20}$ Others have described acetazolamide reducing CSF production after TAAAR, which seems reasonable for treating delayed SCD. ${ }^{21}$ Paraplegia lasting beyond 24 to 48 hours is probably permanent.
Permanent SCD necessitates measures to avoid venous thromboembolism and manage bowel and bladder dysfunction. Because there is little high-quality evidence of successful postoperative strategies to prevent or treat delayed paraplegia, clinical trials are warranted, which would probably be instructive for both open and endovascular thoracic aortic surgery.

The CSF drain is typically removed 48 to 72 hours postoperatively with a reliable neurologic examination. Proximal leg strength is assessed by raising the knee off the bed; simple foot dorsiflexion or hip rotation is insufficient. If the patient requires prolonged ventilation, then the drain may remain for 72 to 96 hours. The CSF drain is clamped for 6 hours before removal, followed by 4 hours of bed rest with frequent neurologic assessments. Complications of CSF drainage include post-dural puncture headaches and a bloody drain. Headaches, which about $10 \%$ of patients experience, are initially managed with caffeine ingestion. In a previous study from our institution, approximately one third of patients needed an epidural blood patch within 24 to 48 hours after drain removal. ${ }^{22}$ Patients with Marfan syndrome were more than twice as likely to have post-dural puncture headache requiring a blood patch for relief. As 2 other high-volume centers have reported, the incidence of bloody CSF drain is $3 \%$ to $5 \%$, with a $1 \%$ to $2 \%$ incidence of drain-related neurologic complications. ${ }^{23,24}$ The drain is removed if it becomes bloody. Asymmetric weakness not attributable to incisional pain is evaluated with computed tomography (CT) or magnetic resonance imaging for spinal hematoma, which may require neurosurgical consultation and evacuation. Finally, in our experience, $2.8 \%$ of patients developed intracerebral hemorrhage, most commonly subdural hematoma $(1.9 \%) .{ }^{3}$ Severe headache with nausea or vomiting warrants emergency CT evaluation for possible subdural hematoma and neurosurgical intervention. ${ }^{22}$

\section{Respiratory}

After TAAAR, patients are brought to the ICU with the double-lumen endotracheal tube should surgical reexploration be necessary. We expect ventilator liberation within 24 to 48 hours. If that appears unlikely, the anesthesiologist replaces the double-lumen tube with a singlelumen one. We begin initial ventilation at $8 \mathrm{~mL} / \mathrm{kg}$ of predicted body weight and transition rapidly to lungprotective ventilation of $6 \mathrm{~mL} / \mathrm{kg}$. These strategies are also optimum for the management of pulmonary contusion, of which there is a variable degree on the left side. We routinely perform bronchoscopy when a single-lumen endotracheal tube is in place for copious secretions or radiographic indications. Successful extubation strategies may include noninvasive ventilation, bilevel positive airway pressure to prevent hypercarbia, and high-flow oxygen (Vapotherm, Exeter, $\mathrm{NH}$ ) through a nasal cannula ${ }^{25}$ to prevent hypoxemia. Significant fluid resuscitation may cause 
airway swelling, so vigilance is required for postextubation stridor and respiratory distress; overall, up to $15 \%$ of patients post-TAAAR require reintubation. ${ }^{3,26}$ For patients with prolonged ventilation, daily spontaneous breathing trials are planned to facilitate liberation from mechanical ventilation. In our experience, approximately $11 \%$ of patients do not achieve ventilator liberation within 2 weeks, necessitating tracheostomy; of these, $28 \%$ have early (operative) mortality. ${ }^{27}$ In extreme cases of postoperative respiratory failure, we have resorted to independent lung ventilation or extracorporeal membrane oxygenation. ${ }^{28}$ Chest tubes are removed when serous drainage is less than $150 \mathrm{~mL} / \mathrm{d}$ and without evidence of blood, chyle, or air leak.

Early mobilization and physical therapy are vital in all patients, including intubated patients. Our initial analgesia strategy includes intravenous acetaminophen, opioidbased patient-controlled analgesia, lidocaine patches, gabapentin, and tramadol, with the goal of minimizing opioid usage before discharge.

After extubation, if cough and voice quality are abnormal, an otorhinolaryngologist performs direct laryngoscopy to assess the vocal cords. About $25 \%$ of patients with extent I and II TAAAR have vocal cord movement impairment $(\mathrm{VCMI})^{3}$ because of the left recurrent laryngeal nerve's proximity to the proximal cross-clamping site. The resultant glottal incompetence from VCMI can cause a breathy voice and impair cough, thereby increasing aspiration and pneumonia risk. ${ }^{29}$ Approximately one quarter of patients with VCMI will require reintubation. Awake, bedside transcervical injection laryngoplasty with absorbable gelatin powder is performed for VCMI to improve glottal gap closure within a few days of discovery to improve pulmonary toilet. ${ }^{30} \mathrm{~A}$ bedside swallow evaluation determines diet advancement.

\section{Cardiovascular}

We use a PA catheter for 24 to 72 hours in all patients. If maintaining a cardiac index $>2.2 \mathrm{~L} / \mathrm{min} / \mathrm{m}^{2}$ requires inotropic support, epinephrine is the preferred agent for augmenting cardiac output and blood pressure. Dobutamine is our second choice; milrinone is avoided for its systemic vasodilatory effects. Patients with significant left ventricular hypertrophy need adequate preload and sufficient time in diastole to avoid tachycardia for optimal hemodynamics. In general, we monitor cardiac output, mixed venous oxygen saturation, urine output, and serum lactate to guide resuscitation.

In our experience, the incidence of atrial fibrillation was $23 \%$; age and need for visceral perfusion were the only predictors. ${ }^{31}$ Atrial fibrillation and loss of the atrial kick may cause hypotension, risking delayed SCD. To avoid hypotension, we prefer a rhythm control strategy with amiodarone over rate control. Although longer-term use (weeks to months) of amiodarone is inadvisable for patients with marginal pulmonary function, short-term use is reasonably tolerated, with low risk for amiodarone pulmonary toxicity. ${ }^{32}$ Timely conversion to sinus rhythm is advised; consequently, early electrical cardioversion should be considered.

The lower-extremity pulse should be palpated for limb ischemia. Asymmetric changes should be promptly evaluated with Doppler ultrasonography. Early and aggressive endovascular intervention may be necessary for limb salvage, with lower extremities monitored for compartment syndrome.

\section{Renal, Fluids, and Electrolytes}

Strategies to reduce SCD risk-greater MAP and volume resuscitation-overlap with AKI prevention. We have found that developing moderate AKI adversely affects survival. ${ }^{33}$ Typically, crystalloid fluid resuscitation is started at 1.5 to $2.0 \mathrm{~mL} / \mathrm{kg} / \mathrm{h}$ and decreased after 24 hours, guided by standard resuscitation parameters. $\mathrm{Pa}-$ tients commonly have a 6 - to 8 - $\mathrm{L}$ positive fluid balance in the first 48 to 72 hours. We use diuretics cautiously to avoid sudden hypovolemia and resultant hypotension risking SCD. Low-dose loop diuretic infusions may be considered. Nevertheless, restoring euvolemia is critical to optimizing pulmonary function and mobility. We avoid restarting renin-angiotensin antagonist medications for several weeks. Multidisciplinary rounding with pharmacists ensures proper dosing of antibiotics and other medications in AKI-vulnerable patients. In patients with a rapid decrease in creatinine clearance, severe oliguria, and teacolored urine, rhabdomyolysis is suspected, and diagnostic serum creatinine kinase measurement and aggressive crystalloid resuscitation are performed. If rhabdomyolysis is diagnosed, then extremity compartment syndrome should be excluded.

Nephrology consultation is advised in patients with advanced AKI. Renal-replacement therapy may be indicated for volume overload, electrolyte derangements, or refractory acidosis. In our practice, the overall incidence of AKI requiring persistent renal-replacement therapy is $7 \%$ but is associated with $57 \%$ operative mortality (unpublished data). Those patients on dialysis who develop respiratory failure necessitating tracheostomy $(3 \%$ of all patients) have $70 \%$ mortality. In patients with preoperative chronic kidney disease, a temporary femoral dialysis line is placed at the conclusion of TAAAR, should early dialysis be necessary.

To preserve potential future dialysis access sites, we avoid peripherally inserted central catheter and subclavian venous lines in patients with AKI. ${ }^{34}$ Finally, to reduce the contrast nephropathy risk, we delay postoperative aortic surveillance CT imaging until the serum creatinine level has normalized and pretreat with isotonic fluids and, selectively, $\mathrm{N}$-acetylcysteine. ${ }^{35}$ 


\section{Gastrointestinal and Nutrition}

Patients immediately begin stress ulcer prophylaxis, and a nasogastric tube remains in place until bowel function returns and nausea and abdominal distension are absent. Postoperatively, oral intake typically starts after 3 to 5 days. In patients mechanically ventilated more than 3 to 4 days, early enteral nutrition begins with trophic feeds through a nasoenteric tube. Adequate nutrition is important, especially for patients with prolonged hospitalization. Gastrointestinal complications require vigilance; unexplained acidemia or increased fluid requirements can indicate mesenteric ischemia, suspicion of which indicates CT imaging or laparotomy. Isolated liver-enzyme elevation may necessitate Doppler ultrasonography to assess the mesenteric vasculature. Gastrointestinal bleeding unresponsive to saline lavage and increased proton-pump inhibitor therapy is evaluated endoscopically. Patients with prolonged ICU stays and unexplained leukocytosis or diarrhea are evaluated for Clostridium difficile infection, and empiric oral vancomycin is initiated.

\section{Bleeding and Hematologic}

Intraoperative measures to reduce postoperative bleeding include administering aminocaproic acid and correcting coagulopathy. Our typical targets are platelet count $>100,000$, international normalized ratio $<1.6$, and fibrinogen count $>200,000$. However, when coagulopathy arises, we recommend point-of-care viscoelastic tests of clotting function (eg, thromboelastography, rotational thromboelastometry), according to institutional preference, although both are used in cardiac surgery. ${ }^{36}$ This strategy allows more selective targeting of blood components, thereby reducing blood-product administration after TAAAR. ${ }^{37}$ We have moved to earlier use of prothrombin complex concentrate (KCentr; CSL Behring, King of Prussia, Pa) in patients with severe coagulopathy.

Early postoperative bleeding can manifest as progressive hemorrhagic shock, elevated chest tube output, or abdominal distention. An unexplained drop in hemoglobin especially associated with hypotension may necessitate CT imaging for hemoperitoneum or hemothorax. Regardless of associated coagulopathy, patients return to the operating room for exploration, hematoma evacuation, and bleeding control. Common sites of bleeding include the spleen, intercostal or lumbar arteries, and anastomoses.

When needed, warfarin therapy is restarted 4 to 5 days postoperatively; unfractionated heparin bridging is reserved for patients without a CSF drain for whom additional procedures (eg, tracheostomy) are being considered. Standard deep vein thrombosis prophylaxis is provided with sequential compression devices. After the CSF drain is removed, chemical prophylaxis is initiated with enoxaparin or subcutaneous unfractionated heparin; subsequently, the patient may be transitioned to factor Xa inhibitors.

\section{MISCELLANEOUS CONSIDERATIONS}

To reduce infections, we are aggressive about removing unnecessary intravascular or urinary catheters, evaluating surgical incisions daily, and closely monitoring for developing pressure ulcers. Prophylactic antibiotics are discontinued 24 hours postoperatively. Patients who required incidental splenectomy are triple-vaccinated against Streptococcus pneumoniae, Haemophilus influenzae type B, and Neisseria meningitidis after the critically ill period, approximately 2 weeks postoperatively or before discharge. ${ }^{3}$

\section{CONCLUSIONS}

The postoperative care of TAAAR patients requires diligent, multidisciplinary cooperation for both the prevention and the early detection of complications, and to promote successful outcomes.

\section{Conflict of Interest Statement}

All authors are in agreement regarding the content of the manuscript. Dr Coselli participates in clinical trials with Bolton Medical; provides consultation for and participates in clinical trials with Medtronic and W.L. Gore \& Associates; and provides consultation for, participates in clinical trials with, and receives royalties and grant support from Terumo Aortic. Dr LeMaire serves as an advisory panel member for Biom'up; serves as a consultant and a principal investigator for clinical studies sponsored by Terumo Aortic; and serves as a co-investigator for clinical studies sponsored by W.L. Gore \& Associates. Dr Preventza provides consultation for and participates in clinical trials with Medtronic and W.L. Gore \& Associates. The remaining authors have no disclosures. This work was not funded by a grant or any other source of external funding. All other authors have nothing to disclose with regard to commercial support.

The authors thank Scott A. Weldon, MA, CMI, FAMI, for illustrations, and Susan Y. Green, MS, and Scientific Publications at Texas Heart Institute for editorial support.

\section{References}

1. Coselli JS, de la Cruz KI, Preventza O, LeMaire SA, Weldon SA. Extent II thoracoabdominal aortic aneurysm repair: how I do it. Semin Thorac Cardiovasc Surg. 2016;28:221-37.

2. Ouzounian M, LeMaire SA, Weldon S, Coselli JS. Open repair of thoracoabdominal aortic aneurysm: step-by-step. Op Tech Thorac Cardiovasc Surg. 2018;23: $2-20$.

3. Coselli JS, LeMaire SA, Preventza O, de la Cruz KI, Cooley DA, Price MD, et al. Outcomes of 3309 thoracoabdominal aortic aneurysm repairs. J Thorac Cardiovasc Surg. 2016;151:1323-37.

4. Coselli JS, Bozinovski J, Cheung C. Hypothermic circulatory arrest: safety and efficacy in the operative treatment of descending and thoracoabdominal aortic aneurysms. Ann Thorac Surg. 2008;85:956-63; discussion 64.

5. Kouchoukos NT, Kulik A, Castner CF. Outcomes after thoracoabdominal aortic aneurysm repair using hypothermic circulatory arrest. J Thorac Cardiovasc Surg. 2013;145:S139-41. 
6. Coselli JS, LeMaire SA. Left heart bypass reduces paraplegia rates after thoracoabdominal aortic aneurysm repair. Ann Thorac Surg. 1999;67:1931-4; discussion 53-8.

7. Coselli JS, LeMaire SA, Koksoy C, Schmittling ZC, Curling PE. Cerebrospinal fluid drainage reduces paraplegia after thoracoabdominal aortic aneurysm repair: results of a randomized clinical trial. J Vasc Surg. 2002;35:631-9.

8. Khan NR, Smalley Z, Nesvick CL, Lee SL, Michael LM II. The use of lumbar drains in preventing spinal cord injury following thoracoabdominal aortic aneurysm repair: an updated systematic review and meta-analysis. J Neurosurg Spine. 2016;25:383-93.

9. Hiratzka LF, Bakris GL, Beckman JA, Bersin RM, Carr VF, Casey DE Jr, et al. 2010 ACCF/AHA/AATS/ACR/ASA/SCA/SCAI/SIR/STS/SVM guidelines for the diagnosis and management of patients with thoracic aortic disease. A report of the American College of Cardiology Foundation/American Heart Association task force on practice guidelines, American Association for Thoracic Surgery, American College of Radiology, American Stroke Association, Society of Cardiovascular Anesthesiologists, Society for Cardiovascular Angiography and Interventions, Society of Interventional Radiology, Society of Thoracic Surgeons, and Society for Vascular Medicine. J Am Coll Cardiol. 2010;55: e27-129.

10. Erbel R, Aboyans V, Boileau C, Bossone E, Bartolomeo RD, Eggebrecht H, et al. 2014 ESC guidelines on the diagnosis and treatment of aortic diseases: document covering acute and chronic aortic diseases of the thoracic and abdominal aorta of the adult. The task force for the diagnosis and treatment of aortic diseases of the European Society of Cardiology (ESC). Eur Heart J. 2014;35:2873-926.

11. Anton JM, Herald KJ. Anesthetic management of open thoracoabdominal aortic aneurysm repair. Int Anesthesiol Clin. 2016;54:76-101.

12. Cheung AT, Weiss SJ, McGarvey ML, Stecker MM, Hogan MS, Escherich A, et al. Interventions for reversing delayed-onset postoperative paraplegia after thoracic aortic reconstruction. Ann Thorac Surg. 2002;74:413-9; discussion 20-1.

13. Etz CD, Luehr M, Kari FA, Bodian CA, Smego D, Plestis KA, et al. Paraplegia after extensive thoracic and thoracoabdominal aortic aneurysm repair: does critical spinal cord ischemia occur postoperatively? J Thorac Cardiovasc Surg. 2008; $135: 324-30$

14. Wong DR, Coselli JS, Amerman K, Bozinovski J, Carter SA, Vaughn WK, et al. Delayed spinal cord deficits after thoracoabdominal aortic aneurysm repair. Ann Thorac Surg. 2007;83:1345-55; discussion 55.

15. Maniar HS, Sundt TM III, Prasad SM, Chu CM, Camillo CJ, Moon MR, et al. Delayed paraplegia after thoracic and thoracoabdominal aneurysm repair: a continuing risk. Ann Thorac Surg. 2003:75:113-9; discussion 9-20.

16. Coselli JS, Green SY, Price MD, Zhang Q, Preventza O, de la Cruz KI, et al. Spinal cord deficit after 1114 extent II open thoracoabdominal aortic aneurysm repairs. J Thorac Cardiovasc Surg. February 12, 2019 [Epub ahead of print].

17. Sandhu HK, Evans JD, Tanaka A, Atay S, Afifi RO, Charlton-Ouw KM, et al. Fluctuations in spinal cord perfusion pressure: a harbinger of delayed paraplegia after thoracoabdominal aortic repair. Semin Thorac Cardiovasc Surg. 2017;29: 451-9.

18. Estrera AL, Sheinbaum R, Miller CC, Azizzadeh A, Walkes J-C, Lee T-Y, et al. Cerebrospinal fluid drainage during thoracic aortic repair: safety and current management. Ann Thorac Surg. 2009;88:9-15.

19. Lima B, Nowicki ER, Blackstone EH, Williams SJ, Roselli EE, Sabik JF III, et al. Spinal cord protective strategies during descending and thoracoabdominal aortic aneurysm repair in the modern era: the role of intrathecal papaverine. $J$ Thorac Cardiovasc Surg. 2012;143:945-52.e1.

20. Urquieta E, Varon J, Lin PH. Reversal of spinal cord ischemia following endovascular thoracic aortic aneurysm repair with hyperbaric oxygen and therapeutic hypothermia. Vasc Endovascular Surg. 2017;51:517-20.
21. Jafarzadeh F, Field ML, Harrington DK, Kuduvalli M, Oo A, Kendall J, et al Novel application of acetazolamide to reduce cerebrospinal fluid production in patients undergoing thoracoabdominal aortic surgery. Interact Cardiovasc Thorac Surg. 2014;18:21-6.

22. Youngblood SC, Tolpin DA, LeMaire SA, Coselli JS, Lee VV, Cooper JR Jr. Complications of cerebrospinal fluid drainage after thoracic aortic surgery: a review of 504 patients over 5 years. J Thorac Cardiovasc Surg. 2013;146:166-71.

23. Weaver KD, Wiseman DB, Farber M, Ewend MG, Marston W, Keagy BA. Complications of lumbar drainage after thoracoabdominal aortic aneurysm repair. $J$ Vasc Surg. 2001;34:623-7.

24. Wynn MM, Mell MW, Tefera G, Hoch JR, Acher CW. Complications of spina fluid drainage in thoracoabdominal aortic aneurysm repair: a report of $486 \mathrm{pa}-$ tients treated from 1987 to 2008. J Vasc Surg. 2009;49:29-34; discussion -5.

25. Frat JP, Thille AW, Mercat A, Girault C, Ragot S, Perbet S, et al. High-flow oxygen through nasal cannula in acute hypoxemic respiratory failure. $N$ Engl J Med. 2015;372:2185-96.

26. Etz CD, Di Luozzo G, Bello R, Luehr M, Khan MZ, Bodian CA, et al. Pulmonary complications after descending thoracic and thoracoabdominal aortic aneurysm repair: predictors, prevention, and treatment. Ann Thorac Surg. 2007;83:S870-6; discussion S90-2.

27. Songdechakraiwut T, Aftab M, Chatterjee S, Green SY, Price MD, Preventza O, et al. Tracheostomy after thoracoabdominal aortic aneurysm repair: risk factors and outcomes. Ann Thorac Surg. 2019;108:778-84.

28. Chatterjee S, Mulvoy W, Preventza O, de la Cruz KI, LeMaire SA, Coselli JS ECMO for acute respiratory distress syndrome after thoracoabdominal aortic aneurysm repair. Ann Thorac Surg. 2018;106:e171-2.

29. DiLisio RP, Mazzeffi MA, Bodian CA, Fischer GW. Vocal cord paralysis after aortic surgery. J Cardiothorac Vasc Anesth. 2013;27:522-7.

30. Chen DW, Price MD, LeMaire SA, Coselli JS, Liou NE, Ongkasuwan J. Early versus late inpatient awake transcervical injection laryngoplasty after thoracic aortic repair. Laryngoscope. 2018;128:144-7.

31. Dolapoglu A, Volguina IV, Price MD, Green SY, Coselli JS, LeMaire SA. Cardiac arrhythmia after open thoracoabdominal aortic aneurysm repair. Ann Thorac Surg. 2017; 104:854-60.

32. Wolkove N, Baltzan M. Amiodarone pulmonary toxicity. Can Respir J. 2009; 16 : 43-8.

33. Chatterjee S, LeMaire SA, Amarasekara HS, Green SY, Price MD, Yanoff MS, et al. Early-stage acute kidney injury adversely affects thoracoabdominal aortic aneurysm repair outcomes. Ann Thorac Surg. 2019;107:1720-6.

34. Hoggard J, Saad T, Schon D, Vesely TM, Royer T. Guidelines for venous access in patients with chronic kidney disease. A position statement from the American Society of Diagnostic and Interventional Nephrology, clinical practice committee and the Association for Vascular Access. Semin Dial. 2008; 21:186-91.

35. Kwok CS, Pang CL, Yeong JK, Loke YK. Measures used to treat contrastinduced nephropathy: overview of reviews. Br J Radiol. 2013;86:20120272.

36. Venema LF, Post WJ, Hendriks HG, Huet RC, de Wolf JT, de Vries AJ. An assessment of clinical interchangeability of TEG and RoTEM thromboelastographic variables in cardiac surgical patients. Anesth Analg. 2010;111:339-44.

37. Rahe-Meyer N, Solomon C, Winterhalter M, Piepenbrock S, Tanaka K, Haverich A, et al. Thromboelastometry-guided administration of fibrinogen concentrate for the treatment of excessive intraoperative bleeding in thoracoabdominal aortic aneurysm surgery. J Thorac Cardiovasc Surg. 2009;138: 694-702.

38. Dragomir M, Petrescu DGE, Manga GE, Calin GA, Vasilescu C. Patients after splenectomy: old risks and new perspectives. Chirurgia (Bucur). 2016;111: $393-9$. 